\title{
Analysis and Measurement of Parameters of Quality of Life in Informal Settlements Surrounding of Tehran Metropolis
}

\author{
Yousef Ghaderpour ${ }^{1},{ }^{1}$ Mohammad Reza Arasteh Taleshmekaiil $\left(\mathbb{D},{ }^{2}\right.$ Bahareh Rouki, ${ }^{1}$ \\ Mona Mohemsaz, ${ }^{3}$ Mohammad Hossein Azimi, ${ }^{1}$ and Ali Sadeghpour (i) ${ }^{4}$ \\ ${ }^{1}$ Faculty of Architectural and Urbanism Engineering, Qazvin Islamic Azad University, Qazvin, Iran \\ ${ }^{2}$ Department of Urbanism, Faculty of Marine Science and Technology, Islamic Azad University, \\ Tehran North Branch, Tehran, Iran \\ ${ }^{3}$ Faculty of Urban and Regional Planning, Science and Research Branch, Islamic Azad University, Tehran, Iran \\ ${ }^{4}$ Department of Civil Engineering, Varamin Branch, Islamic Azad University, Varamin, Iran
}

Correspondence should be addressed to Mohammad Reza Arasteh Taleshmekaiil; mohamadreza.arasteh@gmail.com

Received 14 April 2021; Revised 4 June 2021; Accepted 12 June 2021; Published 24 June 2021

Academic Editor: Noorbakhsh Amiri Golilarz

Copyright (c) 2021 Yousef Ghaderpour et al. This is an open access article distributed under the Creative Commons Attribution License, which permits unrestricted use, distribution, and reproduction in any medium, provided the original work is properly cited.

\begin{abstract}
Quality of life is a concept used to describe the development of the welfare of society, and improving the quality of life is one of the most important goals of governments around the world. Informal settlements, as one of the most vulnerable urban areas, are always in unfavorable conditions in terms of various social, economic, and physical indicators. Therefore, the main purpose of this study is to investigate the status of various quality of life indicators in informal settlements around the metropolis of Tehran in Iran. This research is descriptive, analytical, and correlational based on primary data in which the initial data are collected through the documentary and survey (field) method using a questionnaire. The collected data were processed by SPSS and SmartPLS software. Based on the results of the $t$-test, quality of life indices in informal settlements around the metropolis of Tehran, on a Likert scale with an average of 23.2, is at a low level. Also, the results of the PSL path modelling and multivariate regression test show that increasing the quality of social, economic, physical, service, and access indicators, in terms of residents, has the greatest impact on improving the quality of life of this urban fabric and security index. It has the least impact. There is also a significant relationship between indicators, and the mental perspective of citizens changes under social, service, economic, and physical conditions.
\end{abstract}

\section{Introduction}

The 20th and 21st centuries have seen the rapid growth of urbanization and the sudden increase in slums, with only $13 \%$ of the world's population living in cities at the beginning of the industrial age [1]. While, now, by 2020, the world's population has reached 7 billion and 817 million people [2] in which only 3.1 billion live in rural areas [3]. This has led to excessive attention on urban areas and the accumulation of wealth and services in these settlements, while the rural areas have become more deprived. As a result of this escalation of economic, social, and welfare inequalities between urban and rural areas that have occurred in the last century, the city environment has become more attractive to immigrants in a way that many of these immigrants prefer living in the slums of the city rather than living in rural areas. In fact, due to the high cost of housing and financial inability, as well as the low level of technical skills in immigrants, most of them inadvertently go to areas of the city that have minimal facilities, services, and environmental quality [4].

Many people continue to live in such conditions because they are trapped in poverty and are unable to move towards a formal urban lifestyle due to the competitive market forces that exist in the city [5]. This the start point for developing outskirt urban textures that lack any environmental services and quality per se. These settlements grow at the outskirt of metropolises under the title of informal settlements. 
Informal settlements have been recognized as a global challenge for decades. In countries such as India, Egypt, South Korea, and Iran, such settlements represent a method of urbanization $[6,7]$. According to the studies of the Ministry of Housing and Urban Development, studies have been conducted so far about informal settlements in 77 cities in the form of 851 informal neighbourhoods with an area of 52,443 and a population of more than 5,900,000 people. Tehran, Mashhad, Zahedan, Tabriz, and Isfahan are the cities with the highest number of informal settlements, respectively, and in need of improvement [8]. Despite the long history of urbanization and recognition by government policies, living conditions in these areas are very difficult [9]. Despite years of efforts to strengthen the urban status, in the current situation, these neighbourhoods are commonly identified with severe insecurity and vulnerability in the social, economic, and physical sectors. Residents of these urban neighbourhoods also struggle with basic services such as water, health, electricity and environmental hazards, and air pollution [6].

Inadequate urban environmental conditions and their ongoing consequences on quality of life in informal settlements have become the most controversial aspect of cities. Cities and towns in developing countries such as Iran are growing rapidly [10].

In informal urban settlements, the rate and scale of physical growth and development and population density have exceeded acceptable standards of public health, physical infrastructure development, environmental safety, and sustainable economic growth. Therefore, the quality of life is significantly reduced compared to other areas [11].

Therefore, a comprehensive study and assessment of living conditions should be conducted with scientific criteria to plan for the improvement of living conditions based on a comprehensive cognitive. In the meantime, the criterion of quality of life can indicate the achievement of such a goal because it is a comprehensive concept that covers various aspects of human life [12]. Quality of life is one of the most important issues facing the world today. Also, improving the quality of life is one of the most important goals of different governments and states [13].

In the past few decades, paying attention to the quality of life and improving it in urban and rural settlements has been one of the main goals of human development programs and has continually influenced the policies of countries around the world $[14,15]$.

The term "quality of life" is used to assess the general well-being of individuals in societies, but its meaning is very complex and very comprehensive and varies according to the time and beliefs of the individuals [11]. Quality of life is a concept to show how to meet human needs and a criterion for understanding satisfaction or dissatisfaction with various aspects of life [16].

The World Health Organization defines the quality of life as people's perception of their position in life in the context of the culture and value systems in which they live and according to their goals, standards, expectations, and concerns [17]. According to Ghasemi et al., the quality of life depends on how people live, feel, and understand daily life.
This includes aspects such as health, education, housing [18], employment, and participation in decision-making [18-20]. Dovey points out that quality of life is a term that has emerged as a concept of living conditions, health and physical safety, and mental and social ability [21]. Richards and Mutsonziwa consider the level of quality of life as how each individual or group views the society [22].

As mentioned, the world's urban population is about twice that of the rural population, and it is predicted that, by 2030, this gap will increase even more in developing countries [23]. One of the consequences of these population shifts and urbanization is the increase of urban poverty and the physical development of cities [24]. The emergence this phenomenon is informal settlements with the main feature of urban poverty and informal development of the city body [25]. According to the United Nations estimations, around 1 billion people, 14 per cent of the world's population, live in these suburban areas, which can be doubled by 2030 [26, 27].

Ono introduces these settlements in Nairobi as amazing spaces with planned growth and high population density, which accommodates most of the poor [28]. Verma finds living conditions in Indian slums very difficult. According to him, quality of life is summarized in a wide range of fields such as international development, health, political sciences, urban environment, education, leisure, and social affiliation [29]. Dovey et al. believe that a wide range of social, economic, and political complexities will lead to the creation of informal settlements around metropolitan areas [30]. These settlements are generally defined as the rapid, unauthorized, and organic growth of new urban neighbourhoods. These settlements have always been considered as an attraction for migration and affordable housing in the face of a lower quality of life [31, 32].

All these approaches are in line with achieving sustainable urban development. Quality of life, in the category of sustainable development, emphasizes continuity, coordination, and stability of development, including the economy, environment, culture, living conditions, and other factors [33]. Quality of life findings can be used to identify past policy strategies and design future planning policies [34]. Such design has some fundamental structures and it can be done using many artificial intelligence approaches in intelligent systems [35-42], which we cannot review all of them as it goes beyond the scope of this research. Santos and Martinez point out that local social participation in quality of life studies can be an important support for setting longterm policies and goals [43]. The issue of quality of life has entered the urban planning and development literature since the 1960s. This view was further explored by geographers such as Harvey and Smith [44, 45].

In Iran, as in other middle-income developing countries, rapid urbanization in the last five decades has led to the expansion of informal settlements in areas around metropolitan areas [46]. Among the big cities of Iran, the metropolis of Tehran is facing more informal settlements and self-growth areas in its outskirts or middle, rather than other cities of the country due to various factors such as being political-administrative central of the country and the concentration of the most economic, industrial, and service activities in it. 
The emergence and growth of informal settlements in Iran is the result of government policies since 1980. During this period, incomplete efforts have been made to improve the conditions of these settlements. However, the main question is what indicators are important in improving the conditions of informal settlements and why? The day-to-day growth of these areas and the increasing complexity of the social, economic, physical, service, and security situation show that we are paying attention to the different dimensions of these urban contexts.

The main approach of this study is to investigate the quality of life in these settlements and the impact of quality of life indicators of improving the situation in these areas. The varieties of indicators used in urban quality of life studies are innumerable. This is obvious given the multidimensionality of the concept of quality of urban life. It is generally assumed that each indicator reflects the size and importance of a particular dimension of the quality of urban life. This assumption is based on the fact that the quality of urban life can be separated into a set of components or dimensions, and if these components are properly combined, a value for the quality of urban life can be obtained.

In this study, various indicators of quality of life have been studied, and finally, according to the type of context studied, the 5 main physical, access and service, security, social, and economic indicators in 13 components (Figure 1) have been selected. These indicators of Islamshahr are considered as an informal settlement around the metropolis of Tehran in Iran. As a result, it seems that, in order to formulate an appropriate strategy, we need more work and research in various fields in these urban areas. Therefore, the present study attempts to measure the criteria and indicators related to quality of life at the desired neighbourhoods (Figure 1) and specify the lack or suitableness of each of the indicators.

The indicators presented in Figure 1 have been examined based on the current situation and the indicators presented in previous studies, and finally, by matching all the indicators, 5 indicators in 13 criteria have been selected. These indicators are the basis for compiling a questionnaire in the form of related questions on which the collection of study data has been done.

\section{Materials and Methods}

The study, to develop criteria and indicators of quality of urban life and upgrading these criteria in informal urban contexts, requires a comprehensive approach to planning and study that while identifying and classifying criteria and indicators of quality of urban life, there needs to be a causal relationship between these indicators.

The research methodology in the present study is descriptive, analytical, and correlational and the data collection method is a documentary and survey in which the survey part has been done through a questionnaire method.

To assess the quality of life in informal and peripheral settlements around the metropolis of Tehran, with emphasis on Mozaffariyeh, Mianabad, and Ziaabad areas in Islamshahr, five main dimensions of physical, economic, social, services (accessibility), and security have been used. Each of these dimensions has subcategories that have been explored. The sampling method was simple and random and the sample size was estimated using the Cochrane methodology.

According to the census of the Statistics Center of Iran in 2016, the population in the three mentioned neighbourhoods of Mianabad, Ziaabad, and Mozaffariyeh are about 53234 people [8]. This population is considered as a statistical population in which a statistical sample of 381 people was selected and a questionnaire was distributed among them.

Collecting and preprocessing of data is a very crucial step in any statistical or analytical analysis [47-52]. The data obtained from the questionnaire were analysed using SPSS software and statistical analysis of PLS. In the section of descriptive statistics, abundance, frequency percentage, mean, etc., eere used, and in the inferential statistics section, due to the conversion of research variables into quasi-distance variables, in order to calculate the importance or existence of any feature, numbers of 5, 4, 3, 2, and 1 were, respectively, assigned to very high, high, medium, little, and very little options; then, the score of each option was calculated by multiplying the frequency by the score of each option. Then, with the option's scores, the score of each question was obtained, where average scores were calculated by dividing the sum of the points by the number of people who answered to that option. Given that the average score of each question is a number between 1 and 5 , so this criterion was used to assess the importance of questions or options. Then, some parametric tests such as t-test and multivariate regression in SPSS software environment have been applied [53] and PLS path modelling has been used with the help of SmartPLS software [42, 53-58]. Cronbach's alpha test was used to calculate the reliability of the questionnaire questions in which the reliability score is equal to 0.89 and at an acceptable level [59-65].

\section{Results and Discussion}

Between 1992 and 2007, with the development of Tehran metropolis and the filling of vacant lands, the influx of capital and special social groups into the almost untouched suburban lands of the southern and southwestern part of the metropolis of Tehran began; physical disorders peaked and construction of uncoordinated textures of sheds, informal urban textures, annexation in villages, and self-growth cities was observed in abundance in Tehran.

As of now, despite serious measures to prevent illegal construction, the destruction of gardens and land occupation has continued. Due to the indecision of landowners and lack of appropriate action by the municipality, a significant part of the area was separated and was built in the form of disordered and self-growth textures and sheds which cause the development of the urban area in an attached or detached from around Tehran as much as possible.

Since the quality of life is a relative issue and the individual characteristics and living conditions of each person have a great impact on the quality of life of each person, part of the questionnaire is dedicated to descriptive information. The descriptive statistics of the research include age, gender, marital 


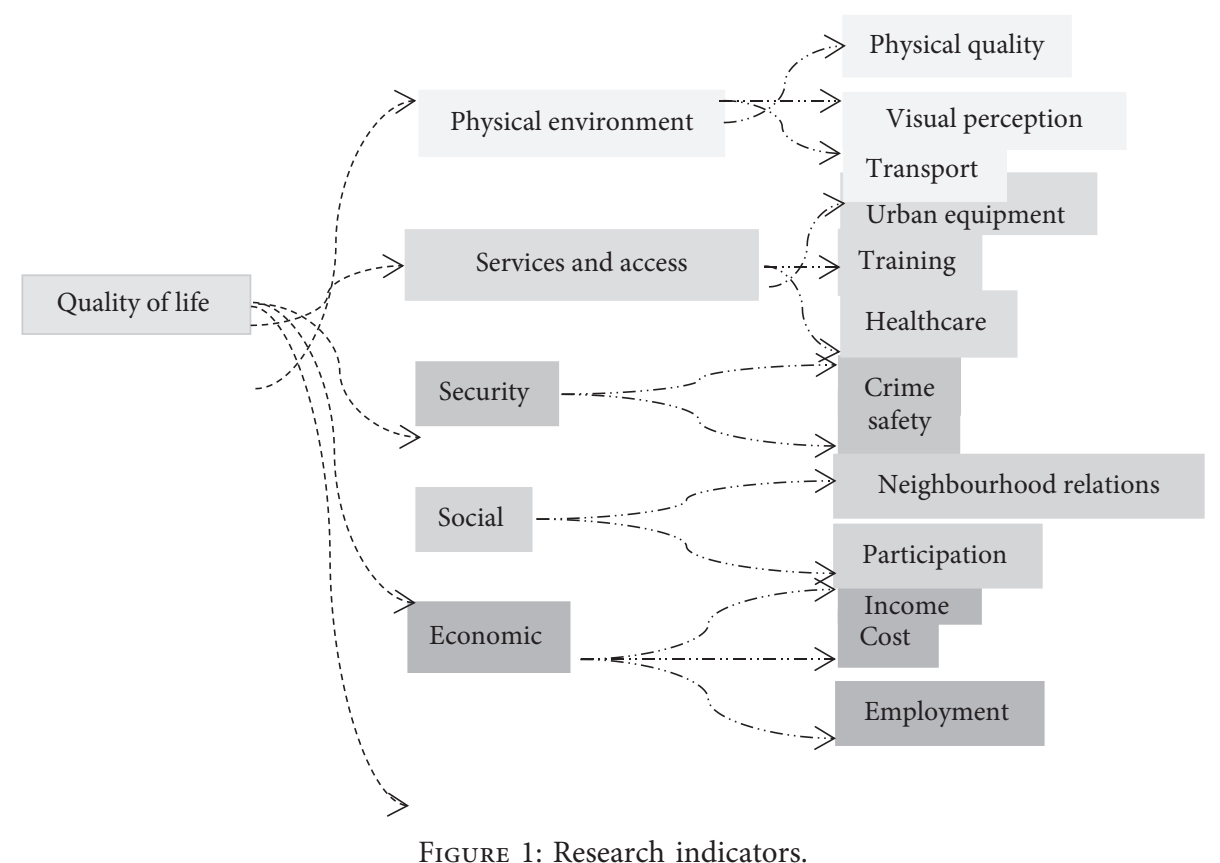

status, education, homeownership, length of residence in the neighbourhood, age of the residential house, type of vehicle, and reason for living in these contexts, which is shown in Table 1.

Here, we have examined in detail some of the descriptive information and personal characteristics that are more important in the discussion of the quality of life.

In terms of age, the statistical sample was $4.1 \%$ of $12-18$ age range, $45.5 \%$ of $19-35$ age range, $20.9 \%$ of $36-45$ age range, $21.3 \%$ of $46-60$ age, and $74 \%$ were older than 60 years.

In terms of gender, $62.4 \%$ were male and $37.6 \%$ were female. In terms of job difference, $2.3 \%$ of the samples were employees, $40.2 \%$ were self-employed, $14.7 \%$ were retired, $5.7 \%$ were student, $25.5 \%$ were housewives, and $11.7 \%$ were unemployed.

Also, the residence period in the neighbourhood of the sample size is $3.6 \%$ between $1-5$ years, $7.4 \%$ between $5-10$ years, $12.8 \%$ between $10-15,21 \%$ between $15-20$ years, and $56.2 \%$ over 20 years in these areas.

In terms of the residential house age, the status of respondents was as follows: age of their homes of $2.8 \%$ was between $1-5$ years old, $47 \%$ was between $5-10,8.1 \%$ was between $10-15,12.3 \%$ was between $15-20$ years, and $72.1 \%$ was more than 20 years and in terms of ownership, and $82 \%$ of respondents were landlords and $18 \%$ were tenants.

Also, the average of each quality of life indicators is shown in Table 2.

3.1. Measuring the Dimensions of Quality of Life from the Perspective of Informal Residents. In this research, the average of the sample is compared with the value of 3 , which is considered the average value. If the average of each index is significant and has a significant difference to the value of $(P<0.05)$, it indicates that the level of satisfaction with the quality of life is below average.
To assess the level of quality of life in the intended contexts around the metropolis of Tehran, indicators, including physical, economic, social, access services, and security have been used. The one-sample test was used to assess the status of each indicator and the level of satisfaction of each. The $T$-test was also taken for each of the subindicators and their sum was analysed. Table 3 summarizes the obtained results.

As can be seen in Table 3, the quality of life in three neighbourhoods of Mianabad, Ziaabad, and Mozaffariyeh is low based on the results of the T-test. Also, in terms of indicators and subindicators, the state of satisfaction with physical, economic, social, access services, and security features has been significant and shows a low quality of life in all aspects of quality of life.

The results show that, in all factors affecting the quality of life, the actual mean value is greater than the assumed mean; in other words, the average level of life satisfaction in the dysfunctional urban context is considered as the $T$ value. Since, in informal settlements, renovations or appropriate constructions are rarely done (mostly due to the poor economic situation of the residents of these neighbourhoods), so most of the texture of these neighbourhoods is worn out and based on the average, minimum satisfaction is in the physical dimension. Also, due to the residency of lowincome people and immigrants and vulnerable groups (addicts) in these neighbourhoods, the level of economic satisfaction is very low.

However, on the contrary, due to residents pressured by the government through various laws and different organizations, as well as their social distance from urban life and low level of access to services, there is a high level of solidarity and unity between them, and the level of social solidarity is high in this area.

Since, in these neighbourhoods, services are not provided by the government and the municipality, due to the 
TABle 1: Research descriptive data.

\begin{tabular}{|c|c|c|c|}
\hline Indicator & Percent & Indicator & Percent \\
\hline Vehicle type & \multicolumn{3}{|c|}{ Job } \\
\hline Subway & 12 & Employee & 2.3 \\
\hline Bus & 45.2 & Freelance & 40.2 \\
\hline Taxi & 15.7 & Retired & 14.7 \\
\hline Private car & 9.4 & Student & 5.6 \\
\hline Bicycles and motorcycles & 7.3 & Housewife & 25.5 \\
\hline Other & 10.4 & Unemployed & 11.7 \\
\hline Duration of residence & \multicolumn{3}{|c|}{ Age } \\
\hline $1-5$ years & 3.6 & $12-18$ years & 4.1 \\
\hline 5-10years & 7.8 & $19-35$ years & 45.9 \\
\hline $10-15$ years & 12.4 & $36-45$ years & 20.9 \\
\hline $15-20$ years & 21 & $46-60$ years & 21.3 \\
\hline 20 and up & 56.2 & 60 and up & 7.8 \\
\hline Marital status & \multicolumn{3}{|c|}{ Gender } \\
\hline Married & 69.6 & Man & 62.4 \\
\hline Single & 30.4 & Female & 37.6 \\
\hline Oldness of residential building & \multicolumn{3}{|c|}{ Education } \\
\hline $1-5$ years & 28 & Elementary school & 30.7 \\
\hline $5-10$ years & 11.7 & Guidance & 19.3 \\
\hline $10-15$ years & 18.1 & Diploma & 35.2 \\
\hline $15-20$ years & 12.3 & Bachelor & 10.2 \\
\hline 20 and up & 29.1 & Master's degree and higher & 4.6 \\
\hline Housing ownership & \multicolumn{3}{|c|}{ Reason for living in the neighborhood } \\
\hline Owner & 82 & House price & 25.4 \\
\hline \multirow{3}{*}{ Rental } & 18 & Proximity to work & 23.3 \\
\hline & & Proximity to relatives & 30.2 \\
\hline & & Other & 21.1 \\
\hline
\end{tabular}

TABLE 2: Average level of satisfaction in quality of life indicators.

\begin{tabular}{lccccc}
\hline Indicators & Very little (\%) & Low (\%) & Medium (\%) & Much (\%) & Very much (\%) \\
\hline Security & 35.20 & 26.30 & 30.90 & 7.60 & - \\
Physical environment & 12 & 40 & 32.50 & 10.30 & 5.20 \\
Accessibility and services & 33 & 41.10 & 7.60 & - & - \\
Economic & 60.80 & 31.30 & 37.50 & 16.70 & 14.50 \\
Social & 12.40 & 18.90 & & - \\
\hline
\end{tabular}

TABLE 3: Obtained results from $T$-test.

\begin{tabular}{|c|c|c|c|c|}
\hline Quality of life indicators & Average & Test value & $T$ & Significant level \\
\hline Physical environment & 2.62 & \multirow{6}{*}{3} & -13.318 & 0.000 \\
\hline Economic & 1.56 & & -34.561 & 0.000 \\
\hline Social & 3.71 & & 16.532 & 0.000 \\
\hline Services and accessibility & 1.68 & & -62.868 & 0.000 \\
\hline Security & 2.03 & & -45.786 & 0.000 \\
\hline All indices & 2.33 & & -36.521 & 0.000 \\
\hline
\end{tabular}

informal recognition, and also insecure places, due to the presence of criminals and addicts, and the level of satisfaction in terms of access services and security is low.

3.2. Determining the Share of Important Indicators in the Quality of Life (Using Multivariate Regression). One of the important defaults of linear regression is related to the distribution and dispersion of variable data in which data of the research variables should be normal or close to normal [66-70]. The Kolmogorov-Smirnov test is used to solve this problem. The results of the Kolmogorov-Smirnov test in Table 4 show that the distribution of research data is normal and has a normal statistical proportion so that the statistical value of this test for the data of this research is equal to 0.792 .

$R$, which is sometimes known as the correlation coefficient, fluctuates between zero and one. The closer the value of this correlation is to one, the stronger the correlation is between the independent variables and the dependent variables. According to Table $5, R$ value is equal to 0.921 , which indicates an acceptable and high value. $R$ square is the coefficient for determining the research indicators, and the 
TABLE 4: Kolmogorov-Smirnov test to check the normality of the data.

Kolmogorov-Smirnov test

\begin{tabular}{lr}
\hline Kolmogorov-Smirnov Z & 0.792 \\
Significant level & 0.566 \\
Result & Normal data distribution \\
\hline
\end{tabular}

TABLE 5: Statistical summary of model fitting.

\begin{tabular}{lcc}
\hline Coefficient of determination & $R$ square & Correlation coefficient $(R)$ \\
\hline 0.866 & 0.868 & 0.921 \\
\hline
\end{tabular}

value of this coefficient also fluctuates between zero and one, and the closer it is to the value of one, the more it indicates that the independent variables were able to explain the amount of the dependent variable.

Therefore, since the coefficient of determination is equal to 0.868 , it shows that approximately $0.866 \%$ of the total changes in the level of satisfaction with the quality of life in informal contexts around the metropolis of Tehran can be determined with the five dimensions of this research.

We have followed fair comparison rules to reach unbiased results and comparisons regardless of the computing environment [71-77]. The sig value of the analysis of variance column was used to check the correctness of the regression model fitting. As shown in Table 6, the value of the significance level is equal to zero, and since the value obtained is less than 0.05 , it follows that the used regression model is significant and a good predictor of the dependent variable which is quality of life.

Since the scale of independent variables is often composed of different units in regression analysis, the standardized regression coefficients help the researcher to determine the relative contribution of each independent variable in explaining the changes of the dependent variable by considering other specific independent variables.

In this test, the higher the beta coefficient of a variable, so is its role in predicting changes in the dependent variable. According to the significance test of the coefficients, it can be concluded that all the dimensions of the research have a positive effect on the quality of life. Also, standard coefficients have been used to compare the effect of independent variables on the dependent variable which is quality of life.

Based on these obtained coefficients, the share of each of the considered dimensions to measure the quality of life in the informal settlement of informal neighbourhoods around Tehran was the highest, respectively, on the social dimension with a standard coefficient of 0.48 , economic dimension with a standard coefficient of 0.443 , physical dimension with a standard coefficient of 0.327 , service and access dimension with a standard coefficient of 0.328 , and security dimension with a standard coefficient of 0.233 .

ANOVA analysis also shows whether the regression model can significantly and appropriately predict the changes of the dependent variable and according to Table 6; the obtained sig value is less than 0.05 , which indicates that the used model is a good predictor of the quality of life's variable.

3.3. Measuring the Impact of Indicators on the Quality of Life (PLS Route Modelling). Smart PLS as an alternative to multiple regression and covariance-based structural equation modelling. PLS is often used as a method of componentbased structural equations (SEM) or variance-based structural equations (VEM). The results of the PLS analysis in Figure 2 are based on a set of independent variables (quality of life indicators) that affect the dependent variable (quality of life). The results are shown as a regression model to assess the quality of life through a set of indicators. The results show the effect coefficients of the dependent independent variables.

It is very vital to have a clear conceptual model and determine the best way for measuring and assessment of the qualitative data $[42,55,78-84$.] The conceptual model tested in the standard mode or PLS algorithm and the path coefficient are presented in Figure 2. The numbers shown on the path of the structures together are called the path coefficient. This number represents the standardized beta in the regression or correlation coefficient of two factors and is presented to examine the degree of the direct impact of one variable on another variable. The numbers displayed on the path between operations and indicators represent the factor load in reflective models.

According to Figure 2, which shows the status of the research, the measurement model in the standard mode, and according to the values of path coefficients that represent the standardized beta in the regression or correlation coefficient of two instruments, we can measure the effect of each of the independent variables which are the five dimensions of quality of life in this study on the dependent variable; the impact of these dimensions can also be ranked.

Based on the internal or structural model of the research, the social dimension of quality of life with a coefficient of 0.451 had the greatest impact on quality of life in the studied area. Then, the economic dimension with a path coefficient of 0.436 , the economic dimension with a path coefficient of 0.305 , and then services and access dimension with a path coefficient of 0.232 were placed in the next ranks, and finally, the security dimension with a path coefficient of 0.215 had less impact on quality of life in the studied area. 
TABLE 6: Standardized regression coefficients of independent variables on the dependent variable.

\begin{tabular}{|c|c|c|c|c|c|}
\hline \multirow{3}{*}{ Indicators } & \multirow{2}{*}{\multicolumn{2}{|c|}{$\begin{array}{c}\text { Analysis of variance } \\
\text { ANOVA }\end{array}$}} & \multirow{3}{*}{$T$} & \multirow{3}{*}{ Impact factor beta } & \multirow{3}{*}{ Significant level } \\
\hline & & & & & \\
\hline & $\mathrm{F}$ & Sig & & & \\
\hline Physical environment & & & 15.475 & 0.327 & 0.000 \\
\hline Economic & & & 16.791 & 0.443 & 0.000 \\
\hline Social & 586.939 & 0.000 & 17.105 & 0.488 & 0.000 \\
\hline Services and accessibility & & & 12.498 & 0.238 & 0.000 \\
\hline Security & & & 11.982 & 0.233 & 0.000 \\
\hline
\end{tabular}

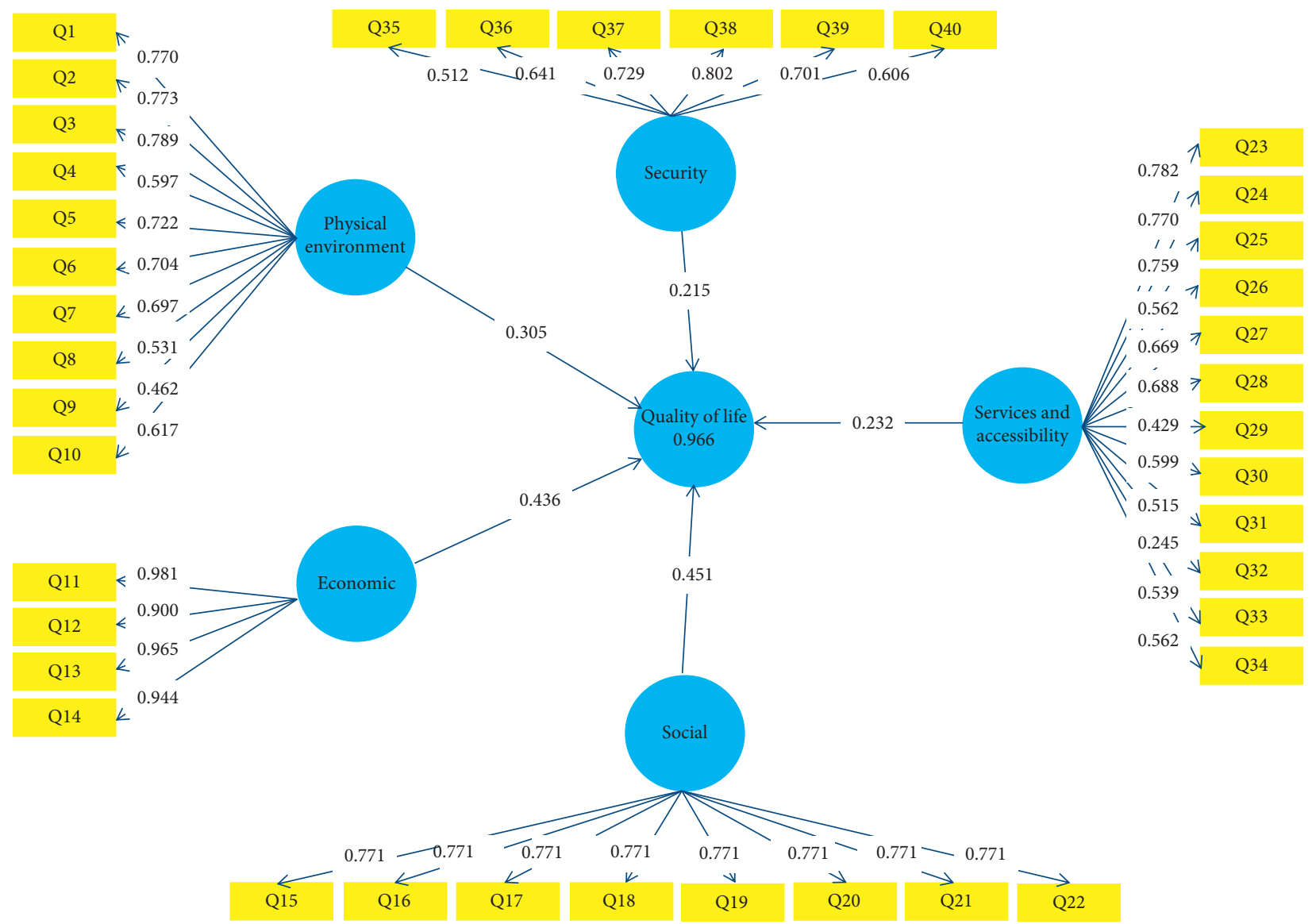

FiguRE 2: Standard research: the measurement model.

\section{Conclusions}

According to the results of the research, the quality of life in informal and marginal urban areas is not very favorable so that the average quality of life indicators in these urban neighborhoods is equal to 2.34 in the Likert range (1-5), which is lower than the average. Also, the results of the $T$-test show that the level of satisfaction with the quality of life in these urban areas is in an unfavorable situation.

$T$-test on indicators and subindicators demonstrate that the level of satisfaction with all aspects of quality of life is low. Also, based on the results of the regression test and based on the obtained beta coefficients, the share of each of the dimensions intended to measure the quality of life in informal settlements around the metropolis of Tehran, respectively, are a social dimension with a standard coefficient of 0.488 , the economic dimension with a standard coefficient of 0.443 , the physical dimension with the standard coefficient of 0.23 , the service and access dimension with the standard coefficient of 0.238 , and the security dimension with the standard coefficient of 0.233 .

Also, based on the results obtained from the structural PLS model, the social dimension of quality of life with a path coefficient of 0.451 had the greatest impact on quality of life in the studied area. The economic dimension with a path coefficient of 0.436 , the physical dimension with a path coefficient of 0.305 , and then services and access dimension with a path coefficient of 0.232 were placed in the next ranks; finally, the security dimension with a path coefficient of 0.215 had less impact on quality of life in the studied area.

Therefore, by recognizing the impact of each of these components and their prioritization and planning to 
improve these components, the level of life satisfaction in the studied areas can be increased.

By examining this model in detail, the most important factors that have reduced the quality of life in this neighborhood can be related to economic and access services' indicators, which with an average of 1.65 and 1.68 , respectively, had the lowest level of satisfaction among residents. Most of them work in informal and false parts of the city, such as peddling, which has led to low household income and lack of job security.

Regarding the service and access indicators in these neighborhoods, due to its informal settlement, they are not in a favorable situation in terms of having facilities and municipal services.

The sum of these factors has caused the relative deprivation of neighborhood residents from urban facilities and services. However, the highest level of quality of life indicators is related to the social index, which with an average of 3.71 in the Likert spectrum has favorable conditions compared to other indicators, in which one of the important factors, in this case, is due to the long history of people living in this neighborhood; immigration and low immigration of this neighborhood has caused the people of the neighborhood to be highly dependent on each other.

According to the materials presented in the previous sections, in the study areas around the metropolis of Tehran, there are dysfunctional urban contexts, which are also considered informal settlements.

Also, due to the high participation capacity at the neighbourhood level, due to the low level of household income, some cases lack titled deed, weak infrastructure and municipal services and lack of licenses for construction and improvement or renovation of houses, lack of sufficient democratic institution for reflection of citizens' opinions to the responsible institutions, insufficient trust in managing the unfavorable physical condition of buildings, etc. The possibility of improving the quality of life in these urban contexts is facing major problems.

Now that a general understanding of the characteristics of these urban contexts as well as the level of quality of life indicators in this informal settlement context has been determined, clearly, it does not make sense to abandon it in the hope of long-term economic plans, in which their realization is in a haze of ambiguity due to their own complexity or waiting for these areas to reorganize on their own.

Therefore, it is hoped that the authorities will take steps to organize and solve the problem of this settlement by using the internal potentials of these contexts and relying on public participation. Therefore, the most important strategies that can be mentioned about improving the situation of these neighborhoods are as follows:

The most important solution and the first step in improving the situation of this settlement and increasing the quality of life indicators in these areas should be considered as building trust between the residents of this settlement and urban management so that the involvement of personal and group participation of residents in activities such as renovation and empowerment carried out by urban organizations can be increased.

The city administration must first allocate a certain investment to improve the physical and quality of public spaces in order to gain the trust of the residents of this neighborhood towards the municipality and urban management and, in the future, create a good opportunity to improve other spaces. In fact, increasing the quality of public spaces in this place provides a good intention of trust and interaction for residents towards urban management and the implementation of empowerment and renovation projects.

Create adequate support for receiving bank facilities and reviewing all laws and regulations restricting the access of low-income groups to official facilities and credits and applying appropriate initiatives with the lack of ownership and income fluctuations of the informal sector.

Empowering the neighborhood by creating jobs for residents and preventing them from being attracted to mendacious jobs, one of the most important strategies of it, is the development of the local economy.

\section{Data Availability}

The data used to support the findings of the study are available from the corresponding author upon request.

\section{Conflicts of Interest}

The authors declare that they have no conflicts of interest.

\section{References}

[1] A. Das, "Slum upgrading with community-managed microfinance: towards progressive planning in Indonesia," Habitat International, vol. 47, pp. 256-266, 2015.

[2] W. P. Clock, "7.8 billion people (2020)-worldometer," 2020, http://https//;\%20www.worldometers.info.

[3] Food and Agriculture Organization, "Food and agriculture status 2017," Food and Agriculture Organization, Rome, Italy, 2017.

[4] R. Neuwirth, Shadow Cities: A Billion Squatters, a New Urban World, 1st Edition ed. Routledge, Milton Park, UK, 2016.

[5] K. Okurut, "Household demand for sanitation improvements in low-income informal settlements: a case of East African cities," Habitat International, vol. 44, pp. 332-338, 2014.

[6] A. Bhide, "Informal settlements, the emerging response to COVID and the imperative of transforming the narrative," Social and Economic Development, vol. 22, no. 2, 2020.

[7] D. Roy and N. Menon, "Survey based socio-economic data from slums in Bangalore," Scientific Data, vol. 5, 2018.

[8] A. Engineers, Preparing a Plan for Organizing Informal Settlements in Tehran and Measures to Empower Their Communities with an Emphasis on Urban Improvement, Ministry of Roads and Urbanism, Baku, Azerbaijan, 2017.

[9] J. Montoya and A. Zumelzu, "Indicators for evaluating sustainability in Bogota's informal settlements: definition and validation," Sustainable Cities and Society, vol. 53, 2020. 
[10] M. Mirbehesht, S. Mohamad, and A. Modiri, "Measuring the amount of housing in the neighborhood of Eslam Abad deh Vanak (district 2 of Tehran) with the characteristics of informal housing every day (ANP)," Social Research, vol. 19, pp. 107-132, 2014.

[11] F. L. Amao, "Housing quality in informal settlements and urban upgrading in ibadan, Nigeria (A case study of apete in ibadan)," 2012.

[12] S. Ebadi, Y. Shahriyar, and M. Ghravi, "Assessing the quality of life in informal settlements (Study sample: east area of Sabzevar Kaleidgah)," New Attitudes in Human Geography, vol. 3, no. 6, 2015.

[13] D. Hasanzadeh, "Quality of working life and its impact on productivity," Management Quarterly, vol. 123, pp. 17-31, 2008.

[14] I. Bache, "Measuring quality of life for public policy: an idea whose time has come? agenda-setting dynamics in the European union," European Public Policy, vol. 20, no. 1, pp. 21-38, 2013.

[15] M. Mirghafourvand, M. A. Jafarabadi, N. Tavananezhad, and M. Karkhane, "Predictors of health-related quality of life in Iranian women of reproductive age," Applied Research in Quality of Life, vol. 11, no. 3, pp. 723-737, 2016.

[16] M. Pourtaheri and A. Fatahi, "Assessment quality of life (QOL) in rural areas (Case study: northern Khaveh village, Lorestan province)," Human Geography-Research, vol. 43, no. 76, pp. 13-31, 2011.

[17] W. H. Organization, "Health statistics and information systems," 2019.

[18] P. Theofilou, "Quality of life: definition and measurement," Europe's Journal of Psychology, vol. 9, no. 1, pp. 150-162, 2013.

[19] S. R. Ghasemi, "Health-related quality of life in informal settlements in Kermanshah, Islamic republic of Iran: role of poverty and perception of family socioeconomic status," Eastern Mediterranean Health Journal, vol. 25, no. 11, 2019.

[20] S. Zangane Shahraki, D. Hassanzadeh, and Z. Salary, "Moghadam Evaluation of the quality of life in informal settlements, Tehran metropolitan (case study: Islamabad Salehabad)," Human Geography-Research, vol. 64, pp. 177196, 2014.

[21] K. Dovey, "Informal settlement as a mode of production," in The new Companion to Urban Design, A. L.-S. Tridib Banerjee, Ed., Routledge, London, UK, 2019.

[22] R. Richards and K. Mutsonziwa, "Measuring quality of life in informal settlements in South Africa," Social Indicators Research, vol. 81, pp. 375-388, 2007.

[23] UN-HABITAT, State of the World's Cities 2010/2011: Bridging the Urban Divide, Earthscan, London, UK, 2011.

[24] UN-HABITAT, "Analytical perspective of pro-poor slum upgrading frameworks," 2006.

[25] K. Irandoost and R. Tavallaei, "Defining indicators of informal settlements in Iran," Urban-Regional Studies Research, vol. 6, no. 21, pp. 43-60, 2014.

[26] UN-HABITAT, State of the World's Cities, The Millennium Development Goals and urban sustainability, London, UK, 2006.

[27] UN-Habitat, "The challenge of slums: global report on human settlements 2003," Management of Environmental Quality. An International Journal, vol. 15, pp. 337-338, 2004.

[28] H. Ono, "Understanding the development patterns of informal settlements in Nairobi," Japan Architectural Review, vol. 13, no. 3, pp. 337-338, 2020.
[29] K. Verma, "Quality of life in informal settlement: jaipur," International Journal on Emerging Technologies, vol. 8, no. 1, pp. 586-591, 2017.

[30] K. Dovey, I. Chatterjee, and T. Shafique, "Towards a morphogenesis of informal settlements," Habitat International, vol. 104, 2020.

[31] A. Gilbert, "The return of the slum," International Journal of Urban and Regional Research, vol. 31, no. 4, pp. 697-713, 2007.

[32] A. Roy, "The 21st-century metropolis," Regional Studies, vol. 43, no. 6, pp. 819-830, 2009.

[33] X. Cong, S. Li, and Y. Gong, "Research on sustainable development ability and spatial-temporal differentiation of urban human settlements in China and Japan based on SDGs, taking dalian and kobe as examples," Hindawi, vol. 2021, no. 1, 22 pages, Article ID 8876021, 2021.

[34] Y. J. Lee, "Subjective quality of life measurement in Taipei," Building and Environment, vol. 43, no. 7, pp. 1205-1215, 2008.

[35] J. Xia, "Ultrasound-based differentiation of malignant and benign thyroid Nodules: an extreme learning machine approach," Computer Methods and Programs in Biomedicine, vol. 147, pp. 37-49, 2017.

[36] Y. Zhang, "Towards augmented kernel extreme learning models for bankruptcy prediction: algorithmic behavior and comprehensive analysis," Neurocomputing, vol. 22, 2020.

[37] M. Wang, "Toward an optimal kernel extreme learning machine using a chaotic moth-flame optimization strategy with applications in medical diagnoses," Neurocomputing, vol. 267, pp. 69-84, 2017.

[38] X. Zhao, "Feature selection based on improved ant colony optimization for online detection of foreign fiber in cotton," Applied Soft Computing, vol. 24, pp. 585-596, 2014.

[39] L. Shen, "Evolving support vector machines using fruit fly optimization for medical data classification," KnowledgeBased Systems, vol. 96, pp. 61-75, 2016.

[40] L. Hu, "An efficient machine learning approach for diagnosis of paraquat-poisoned patients," Computers in Biology and Medicine, vol. 59, pp. 116-124, 2015.

[41] C. Li, "Developing a new intelligent system for the diagnosis of tuberculous pleural effusion," Computer Methods and Programs in Biomedicine, vol. 153, pp. 211-225, 2018.

[42] A. Addeh, A. Khormali, and N. A. Golilarz, "Control chart pattern recognition using RBF neural network with new training algorithm and practical features," ISA Transactions, vol. 79, pp. 202-216, 2018.

[43] L. D. Santos, "Monitoring urban quality of life: the porto experience," Social Indicators Research, vol. 80, no. 2, pp. 411-425, 2007.

[44] S. Shahrokhi and M. Chour, "Survey of quality of life indicators in Jiroft city," Space Economics and Rural Development, vol. 12, no. 2, pp. 19-40, 2015.

[45] A. Fatahi and A. Paydar, "Quality of life and human development," 2013.

[46] M. J. M. Tilaki, M. H. Marzbali, and A. Abdullah, "Ariffin challenges of the informal settlements in developing countries' cities: a case study of Iran," World Applied Science, vol. 12, no. 2, pp. 160-169, 2001.

[47] C. Yu, "SGOA: annealing-behaved grasshopper optimizer for global tasks," Engineering with Computers, vol. 28, p. 1, 2021.

[48] J. Hu, "Orthogonal learning covariance matrix for defects of grey wolf optimizer: Insights, balance, diversity, and feature selection," Knowledge-Based Systems, vol. 213, Article ID 106684, 2021. 
[49] H. Chen, "Multi-population differential evolution-assisted Harris hawks optimization: framework and case studies," Future Generation Computer Systems, vol. 111, pp. 175-198, 2020.

[50] H.-L. Chen, "An efficient hybrid kernel extreme learning machine approach for early diagnosis of Parkinson' s disease," Neurocomputing, vol. 184, pp. 131-144, 2016.

[51] D. Zhao, "Chaotic random spare ant colony optimization for multi-threshold image segmentation of 2D Kapur entropy," Knowledge-Based Systems, vol. 216, Article ID 106510, 2020.

[52] X. Zhao, "Chaos enhanced grey wolf optimization wrapped ELM for diagnosis of paraquat-poisoned patients," Computational Biology and Chemistry, vol. 78, pp. 481-490, 2019.

[53] M. M. A. Malakoutian and M. Khaksar, "SBM model based productivity evaluation," ENG Transactions, vol. 1, no. 1, 2020.

[54] A. Addeh and M. Iri, "Brain tumor type classification using deep features of MRI images and optimized RBFNN," ENG Transactions, vol. 2, no. 1, pp. 1-7, 2021.

[55] N. A. Golilarz, "A new automatic method for control chart patterns recognition based on ConvNet and harris hawks meta heuristic optimization algorithm," IEEE Access, vol. 7, pp. 149398-149405, 2019.

[56] M. Taleghani and A. Taleghani, "Identification and ranking of factors affecting the implementation of knowledge management engineering based on TOPSIS technique," ENG Transactions, vol. 1, no. 1, 2020.

[57] S. Kabir, "Uncertainty-aware dynamic reliability analysis framework for complex systems," IEEE Access, vol. 6, pp. 29499-29515, 2018.

[58] X. Xu and H.-L. Chen, "Adaptive computational chemotaxis based on field in bacterial foraging optimization," Soft Computing, vol. 18, no. 4, pp. 797-807, 2014.

[59] M. R. Arasteh Taleshmekaiil, "Investigating the effective factors of renewable energy development in tehran metropolis," Mathematical Problems in Engineering, vol. 2021, Article ID 6636955, 13 pages, 2021.

[60] A. Sadeghpour and G. Ozay, "Evaluation of reinforced concrete frames designed based on previous Iranian seismic codes," Arabian Journal for Science and Engineering, vol. 45, pp. 8069-8085, 2020.

[61] A. Sadeghpour and G. Ozay, "Evaluation of seismic design parameters for reinforced concrete frames retrofitted using eccentric steel bracings," Environmental Engineering, vol. 6, pp. 173-178, 2020.

[62] J. Guo, "Bayesian hierarchical model-based information fusion for degradation analysis considering non-competing relationship," IEEE Access, vol. 7, pp. 175222-175227, 2019.

[63] J. Golrokh and A. Hasan, "A comparison of machine learning clustering algorithms based on the DEA optimization approach for pharmaceutical companies in developing countries," ENG Transactions, vol. 1, pp. 1-8, 2020.

[64] J. Guo, "A Bayesian approach for degradation analysis with individual differences," IEEE Access, vol. 7, pp. 175033175040, 2019.

[65] M. R. Hakan Arslan, "Zeynep mutlum, maximum sound transmission Loss in multi-chamber reactive silencers: are two chambers enough?” ENG Transactions, vol. 2, pp. 1-15, 2021.

[66] W. Zhu, "Evaluation of sino foreign cooperative education project using orthogonal sine cosine optimized kernel extreme learning machine," IEEE Access, vol. 8, pp. 6110761123, 2020.

[67] G. Liu, "Predicting cervical hyperextension injury: a covariance guided sine cosine support vector machine," IEEE Access, vol. 8, pp. 46895-46908, 2020.
[68] Y. Wei, "Predicting entrepreneurial intention of students: an extreme learning machine with Gaussian barebone harris hawks optimizer," IEEE Access, vol. 8, pp. 76841-76855, 2020.

[69] H. Tang, "Predicting green consumption behaviors of students using efficient firefly grey wolf-assisted K-nearest neighbor classifiers," IEEE Access, vol. 8, pp. 35546-35562, 2020.

[70] A. Lin, "Predicting intentions of students for master programs using a chaos-induced sine cosine-based fuzzy K-Nearest neighbor classifier," IEEE Access, vol. 7, pp. 67235-67248, 2019.

[71] Y. Fan, "Rationalized fruit fly optimization with sine cosine algorithm: a comprehensive analysis," Expert Systems with Applications, vol. 157, Article ID 113486, 2020.

[72] E. Rodríguez-Esparza, "An efficient Harris hawks-inspired image segmentation method," Expert Systems with Applications, vol. 155, Article ID 113428, 2020.

[73] S. Jiao, "Orthogonally adapted Harris hawks optimization for parameter estimation of photovoltaic models," Energy, vol. 203, Article ID 117804, 2020.

[74] Z. Xu, "Orthogonally-designed adapted grasshopper optimization: a comprehensive analysis," Expert Systems with Applications, vol. 150, Article ID 113282, 2020.

[75] A. Abbassi, "Parameters identification of photovoltaic cell models using enhanced exploratory salp chains-based approach," Energy, vol. 198, Article ID 117333, 2020.

[76] N. A. Golilarz, H. Gao, and H. Demirel, "Satellite image denoising with harris hawks meta heuristic optimization algorithm and improved adaptive generalized Gaussian distribution threshold function," IEEE Access, vol. 7, pp. 57459-57468, 2019.

[77] R. U. Khan, "An adaptive multi-layer botnet detection technique using machine learning classifiers," Applied Sciences, vol. 9, no. 11, p. 2375, 2019.

[78] J. Tu, "Evolutionary biogeography-based whale optimization methods with communication structure: towards measuring the balance," Knowledge-Based Systems, vol. 212, Article ID 106642, 2021.

[79] Y. Xu, "Enhanced moth-flame optimizer with mutation strategy for global optimization," Information Sciences, vol. 492, pp. 181-203, 2019.

[80] H. Yu, "Dynamic Gaussian bare-bones fruit fly optimizers with abandonment mechanism: method and analysis," Engineering with Computers, vol. 32, pp. 1-29, 2020.

[81] W. Shan, "Double adaptive weights for stabilization of moth flame optimizer: balance analysis, engineering cases, and medical diagnosis," Knowledge-Based Systems, vol. 13, Article ID 106728, 2020.

[82] M. Wang and H. Chen, "Chaotic multi-swarm whale optimizer boosted support vector machine for medical diagnosis," Applied Soft Computing Journal, vol. 88, 2020.

[83] Y. Zhang, "Boosted binary Harris hawks optimizer and feature selection," Engineering with Computers, vol. 43, pp. 1-30, 2020.

[84] M. Naseri, "Evaluation of groundwater resources potential using analytical hierarchy process (AHP) and remote sensing geographic information system (GIS), a case study: Garmsar's catchment basin," Computational Research Progress in Applied Science \& Engineering, CRPASE: Transactions of Civil and Environmental Engineering, vol. 7, pp. 1-8, 2021. 